\title{
OBITUARIES
}

\section{RONALD GREY GORDON}

In a happy community of medical men there is usually one leader, or " father" physician, to whom all turn when any difficult decision is necessary. Such was the position of R. G. Gordon, in Bath, ever since this community lost F. G. Thomson during the war.

He died on April 26, of a sudden cerebral haemorrhage, at the age of 61 and, as many of us would wish for ourselves, dropped in his tracks while still in harness. His health had not been good since he was invalided from West Africa with amoebic dysentery in 1944. He had there had command of a General Hospital, from the time when the 4th Southern General Hospital (T.A.), formed by him in 1938 at Bath, was disbanded in 1942.

He was educated at Charterhouse and Edinburgh University; he gained his M.B. in 1911, and M.D. in 1913. In 1926 he became D.Sc. and a Fellow of the Royal College of Physicians, Edinburgh, where he was a Morison Lecturer. He was a man of wide medical interests and, though he wrote with Thomson in 1926 one of the best books on rheumatic diseases of that decade, his main speciality was the nervous system, psychiatry, and child guidance work. On his retirement from the active staff of the Royal United Hospital, he had become part-time geriatrician to the Bath Clinical area, and he was still, at the time of his death, Physician to the Bath and Wessex Orthopaedic Hospital and a Consultant Physician to the Royal National Hospital for Rheumatic Diseases at Bath.

Perhaps R. G. Gordon will, however, be best remembered for his abilities in organizing and his work for the B.M.A. He was for many years a member of the Council, and did a great deal in connection with the change of format of the British Medical Journal. As a Chairman of Committee he had the rare knack of knowing when to be patient, when to intervene, and what to say in summing up any difficult discussion.

In 1920 Gordon was first appointed to the staff of the Royal National Hospital for Rheumatic Diseases-then named the Royal Mineral Water Hospital. He was a member of the organizing committee of the Conference on Rheumatic Diseases held at Bath in 1928, and edited the Proceedings of the Conference, to which he contributed a paper on " The Effect of Environment on the Chronic Rheumatic Diseases". He was Chairman of the organizing committee of the International Conference on Rheumatic Diseases held at Bath in 1938, and, in addition to writing his excellent book with F. G. Thomson in 1926, contributed a section on "The Autonomic Nervous System in Rheumatoid Arthritis " to the Royal National Hospital, Bath, Bicentenary Survey of Chronic Rheumatic Diseases (1938), and articles on "Gout-an Unsolved Problem" (with J. Barnes Burt, 1939) and "The Nature of Fibrositis and the Influence of Psychological States upon It" (1940) to this Journal. His greatest contribution to rheumatology was, however, his sanity in outlook and, being a physician first and specialist second, the balance of his judgment was always of the greatest value.

As a man he was admired and respected by all, and there could be no more pleasant colleague with whom one might have the privilege of working. He leaves a widow and two sons, both of whom are following in their father's footsteps, one being already a member of the Royal College of Physicians of London.

G. D. KeRSLEY. 